\section{Enlarged parathyroid gland - airway problem}

To the Editor:

Anaesthetic problems associated with hyperparathyroidism are usually related to hypercalcaemic, renal or gastrointestinal symptoms. ${ }^{1,2}$ Patients for emergency parathyroidectomy may be comatose, dehydrated and require postoperative ventilation. ${ }^{3-5}$ We report an additional problem: a large parathyroid adenoma with tracheal deviation leading to difficult tracheal intubation.

A 50-yr-old man was admitted with hyperparathyroidism confirmed by hypercalcaemia, increased alkaline phosphatase, phosphorins, and urinary calcium excretion. Bilateral nephrocalcinosis and typical skeletal changes were seen in the hands and skull. Superior mediastinal CT scan showed a left paratracheal mass causing deviation of the trachea extending into the superior mediastinum (Figure). After premedication with $30 \mathrm{mg}$ pentazocine and $25 \mathrm{mg}$ promethazine $i \mathrm{~m}$, anaesthesia was induced with $5 \mathrm{mg} \cdot \mathrm{kg}^{-1}$ thiopentone before giving $100 \mathrm{mg}$ succinylcholine $i v$. Laryngoscopy was normal but an $8.5 \mathrm{~mm}$ endotracheal could not be passed beyond the vocal cords. Eventually the trachea was intubated with a $7.0 \mathrm{~mm}$ tube. The remainder of the anaesthesia was uneventful.

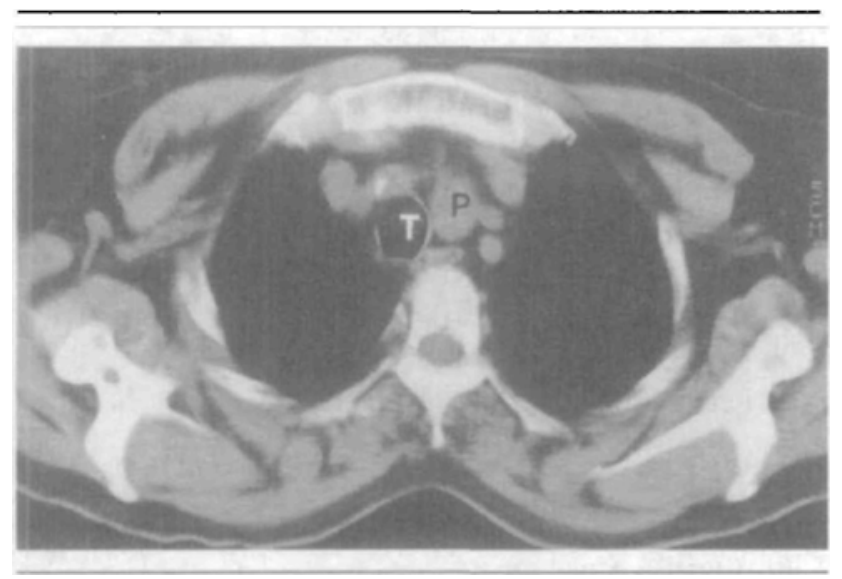

gland $(P)$ causing deviation of the trachea $(T)$ to the right.

Although the principal concern in anaesthetizing patients with hyperparathyroidism is their systemic manifestations, in this patient tracheal deviation by a parathyroid adenoma posed a serious intubation problem. As with thyroid goitres, the possibility of com- promised airway with parathyroid adenomas should be kept in mind.

\section{Soma Kaushik mS DA MNAMS \\ SGPGIMS Lucknow, India}

\section{REFERENCES}

I Villar HV, Wangensteen SL. Surgery of the parathyroid glands. In: Brown BR (Ed.). Anaesthesia and the Patient with Endocrine Disease. London: Blackwell Scientific Publications, 1982.

2 Leshin M. Multiple endocrine neoplasia. In: Wilson J, Foster DW (Eds.). Williams Textbook of Endocrinology, 7th ed. Philadelphia: W.B. Saunders, 1989.

3 Stehling LC, Roizen MF. Endocrine surgery. In: Nunn JF, Utring JE, Brown BR (Eds.). Anaesthesia, 5th ed. London: Butterworths, 1989: 880-6.

4 Disease of the endocrine system. In: Katz J, Benumof $J L$, Kadis CS (Eds.), Anaesthesia in Uncommon Disease. Philadelphia, W.B. Saunders, 1990.

5 Sebel PS. Anaesthesia for thyroid and parathyroid diseases. In: Nimmo WS, Rowbotham DJ, Smith G (Eds.). Anaesthesia, 2nd ed. London: Blackwell Scientific Publications, 1994: 1104-12.

\section{Abbreviated laparotomy and planned re-operation}

\section{To the Editor:}

Occasionally, trauma patients are so haemodynamically and metabolically compromised that prolonged surgery may threaten their survival. In these cases the surgeon may elect to shorten the surgery (abbreviated laparotomy, $A L$ ) and return to the operating room (planned reoperation, PR) when the patient has stabilized. Factors such as profound hypothermia $\left(<33^{\circ} \mathrm{C}\right)$, coagulopathy ( $\mathrm{PT}>15 \mathrm{sec}$ ), acidosis $(\mathrm{pH}<7.18)$ and massive transfusion can lead to this decision. ${ }^{1}$

We encountered three severely traumatized patients where the surgeon opted to conduct an AL. In two, the patients survived to return for PR. The third died of multiple organ failure and disseminated intravascular coagulopathy (DIC) after receiving 50 packs of blood products.

Abbreviated laparotomy is a revival of the abdominal packing employed 50 yr ago. Recently, the surgical criteria and strategies for performing $A L$ and $P R$ have been clearly outlined: ${ }^{2} \mathrm{AL}$ and PR consist of a short intervention aimed at controlling rapid haemorrhage, followed by a period of intense resuscitation in the ICU or PACU during which the patient can be 
prepared for definitive surgery, while procedures such as bowel anastomosis, urethral reconstruction, etc., are undertaken only up to $36 \mathrm{hr}$ after the initial injury when the patient has been adequately stabilized. ${ }^{2}$

Anaesthetists have an important role to play in the decision making on when and where to abbreviate the operation, when to return to the OR and in patient's resuscitation. It is thus surprising that this subject has not been discussed in the anaesthetic literature.

T. Ezri MD, ${ }^{\star}$ P. Szmuk MD, ${ }^{\dagger}$ D. Simon MD, ${ }^{\ddagger}$

D. Geva MD, ${ }^{\star}$ E. Davidson MD,${ }^{\dagger}$ J. Katz,${ }^{\dagger}$

Departments of Anesthesiology, ${ }^{*}$ and Surgery, ${ }^{\ddagger}$ Kaplan Hospital, 76100 Rehovot, Israel and Department of Anesthesiology, ${ }^{\dagger}$ UT-Houston Medical School, Houston, Texas.

\section{REFERENCES}

1 Patt $A, M c$ Croskey BL, Moore EE. Hypothermiainduced coagulopathies in trauma. Surg Clin North Am 1988; 68: 775-85.

2 Burch JM, Ortiz VB, Richardson RJ, Martin RR, Mattox KL, Jordan GL Jr. Abbreviated laparotomy and planned reoperation for critically injured patients. Ann Surg 1992; 215: 476-83.

3 Hirshberg A, Mattox KL. "Damage control" in trauma surgery. Br J Surg 1993; 80: 1501-2. 